\title{
2.6 India: dirty versus clean decentralised energy generation
}

\author{
Ranjit Bharvirkar
}

\subsubsection{Introduction}

Typically, in most of the developed world (and China), provision of electricity to customers has evolved from a decentralised version (e.g. a building served by a small coal-thermal generator in its basement, as seen in the early 1900s in New York city) to massive power plants connected by high voltage transmission lines serving hundreds of thousands of customers over wide swathes of areas (referred to as 'centralised' systems). It is only in the last decade - with the advent of increasingly affordable solar PV - that customer-sited electricity generation has made a comeback in the developed world.

The developing world - including India, which is the focus of this chapter is still somewhere on this path of moving from a decentralised to a centralised electricity system. Unlike the developed world, customers in India still meet their electricity needs through a combination of the centralised power system and decentralised systems served by the private sector (e.g. diesel gensets, kerosene lanterns, lead acid batteries, gas water heaters, etc.). As per India's Central Electricity Authority, as of 31 July 2018, the centralised sector accounts for $\sim 345$ GW of installed generation capacity with an additional 60-90 GW of captive generation installed by large commercial and industrial consumers on their premises (Central Electricity Authority 2018a). Good quality and comprehensive data on the existing decentralised systems mentioned above is non-existent. It is estimated that $\sim 250$ million Indian citizens are not yet connected to the grid - accurate data is non-existent although a few organisations have started conducting surveys to ascertain this figure. The remainder of the population face highly unreliable supply as estimated by relatively crude efforts such as www.watchyourpower.org.

\section{How to cite this book chapter:}

Bharvirkar, R. 2020. India: dirty versus clean decentralised energy generation. In: Burger, C., Froggatt, A., Mitchell, C. and Weinmann, J. (eds.) Decentralised Energy - a Global Game Changer. Pp. 101-112. London: Ubiquity Press. DOI: https://doi.org/10.5334/bcf.g. License: CC-BY 4.0 
The adoption of these decentralised systems had nothing to do with any environmental or policy objectives. They are simply improving the customers' quality of service beyond what was being provided by the centralised system. The decentralised electricity systems are both dirty (in an environmental sense) and expensive. They are also modular and hence, customers are able to invest in them in an incremental fashion. Consequently, the quality of service as received by the customers is a function of their ability and willingness to pay. However, even the combined centralised and decentralised systems are still unable to meet all the electricity needs of millions of customers. Many are simply forced to forego some of their needs.

Historically, there have been no policies or programs to encourage decentralised systems - on the contrary, the policymakers have constantly been under pressure to improve the centralised system so that customers would not have to depend on the dirty and expensive decentralised systems.

The easy availability of clean decentralised technologies (e.g. solar PV, various battery technologies, etc.) that are now significantly cheaper than the existing dirty decentralised technologies is now altering the value proposition and allowing customers to make the substitution both from centralised to decentralised, and within decentralised from 'dirty' to 'clean'.

The performance and cost effectiveness of these new clean decentralised technologies has improved so quickly and significantly, that in many parts of the country, more than half the grid-connected load already finds it significantly cheaper - relative to the marginal retail tariff they face - to install rooftop PV in an attempt to minimise purchasing power from the grid. Bloomberg New Energy Finance (2017) has estimated that the compound annual growth rate (CAGR) since 2013 for adoption of rooftop PV systems for large consumers (typically, commercial and industrial) who face high marginal tariffs across India is $\sim 117$ per cent. The centralised grid in India may never become what it used to be in the developed world - i.e. the sole provider of reliable and cheapest electricity to all customers. In fact, India appears to be moving towards a hybrid system - i.e. a mix of centralised and decentralised systems - that is better able to meet its energy needs.

\subsubsection{A brief history of systemic changes}

Historically, electricity generation started with small generators serving small loads that were located next to the load itself - e.g. the Pearl Street Station in New York in the 1880s served 400 lights and 85 customers and was literally located in the neighbourhood. As the benefits of economies-of-scale were recognised, the sizes of the generating stations grew to 100 s if not 1000 s of megawatts serving 100 s of millions of customers. Inevitably, these stations were located away from the load centres and electricity had to be transmitted over high voltage transmission lines. And over time the small-scale neighbourhood 
or customer-sited generators were eliminated except for a small portion of customers that have a requirement of extremely high levels of reliability.

In most of the developed world (and China), today the main source of electricity is this centralised system (i.e. large-scale generators, high voltage transmission networks, and low voltage distribution networks) that is both reliable and affordable. ${ }^{24}$ The use of centralised systems, driven by their low costs due to economies-of-scale has been common across the developed world outside the power sector also - e.g. natural gas, heat, water, phone/cable, etc. All of these centralised systems are extremely complex - in terms of the number of components in the supply chain that have to work well and in concert with each other - and yet they are also extremely reliable in these countries.

It is only in the last decade or so that customers have begun to adopt distributed generation - e.g. solar PV - largely encouraged through policies/programs where the objectives at least initially did not include either reliability or cost effectiveness. The objectives were numerous including but not limited to environmental protection, climate change mitigation, etc. For a detailed discussion of these objectives see Deshmukh et al. (2012). The value proposition - i.e. quality of the electric service and its cost - from the centralised system for most customers in the developed world (and China) appears to be no longer true across the world as cost of rooftop PV (even unsubsidised) have started edging below the retail tariffs faced by consumers - see for example, Australia and Hawaii.

India, too, embarked on a similar trajectory where the centralised system was expanded rapidly, especially, after gaining Independence in 1947. It is important to note that the data and information presented in this paragraph represents only the centralised system. The installed capacity at that time was $\sim 1.4$ GW serving a population of $\sim 345$ million (Central Electricity Authority 2018b). Today, after more than seventy years, the installed capacity has reached $\sim 345 \mathrm{GW}$ (or more than 200 times that of 1947) while the population has quadrupled.

Of order 250 million citizens in India still do not have access to electricity in as basic a sense as having a wire reaching inside their household. Several efforts to validate the claims of 'electrification' (i.e. www.garv.gov.in) indicate that the definition of 'electrification' continues to be suspect - see for example, Patel (2016), Bansal (2016), Sharma, Josey and Sreekumar (2016), etc. Those who do have access to electricity routinely face power outages that can stretch into several hours per day (Sengupta 2016). Unfortunately, rigorous data on the exact level of 'true' electrification and quality of service is not available in India

24 The exceptions in the developed world in terms of affordability are few - e.g. Australian customers are increasingly finding solar PV (including batteries) to be cheaper than the centralised system. Most of the other examples where distributed solar PV makes sense in the developed world are limited to isolated systems such as those on islands or located in remote areas. 
in a comprehensive manner. Efforts such as Prayas Energy Group's Electricity Supply Monitoring Initiative (ESMI) are providing at least a glimpse about the quality of service. $^{25}$

Rolling blackouts are - in fact - so common for most Indian citizens that in many states the local electricity distribution companies (commonly referred to as 'discoms' in India) provide formal schedules by location and time in local newspapers and online. These schedules are approved by electricity regulators and consumer advocates. Of course - as there is no way to monitor accurately, the discoms can and do deviate from these formally announced schedules. In fact, the infamous power outage in 2012 that blacked out two thirds of India simultaneously, as experienced by citizens in India, was no different in its length than the usual outages they face on a regular basis.

The two key characteristics of electricity from a centralised system in India lack of access and when connected albeit with poor reliability - have, obviously, not resulted in citizens simply foregoing end-uses (e.g. lighting, water heating, electronics, etc.) that rely on electricity completely. After all, the Indian economy has been growing rapidly for several years - averaging 6-7 per cent annually over the last decade - that has in turn led to a rapid growth in the income albeit not uniformly across all income classes. Consequently, Indian citizens have always sought to supplement their consumption of electricity from the centralised system with a wide range of alternatives. ${ }^{26}$ The alternatives that are most prevalent in India include:

1. Electricity: diesel generators and lead-acid batteries.

2. Lighting: kerosene lanterns.

3. Water heating: liquefied petroleum gas (LPG), wood, etc.

4. Water pumping: diesel-fired pumps.

The variations and combinations in which these alternatives are deployed by each user range widely and are driven by factors such as the requirements of the user, ability and willingness to pay, availability of alternatives, etc. These not only vary among users but also vary over time for the same user. And - most important of all - these alternatives are not even acknowledged by the centralised system (i.e. the local electricity distribution company and policymakers) let alone being encouraged and supported. On the contrary - whenever there are periods of the centralised system being able to provide electricity at high level of reliability, the investments of users in these alternatives get completely stranded without any possibility of recourse.

${ }^{25} \mathrm{http}: / /$ www.watchyourpower.org/the_initiative.php.

${ }^{26}$ And this observation applies to other sectors also - e.g. natural gas provided in cylinders in the form of liquefied petroleum gas, water supply service quality is similar to electricity (i.e. unreliable and poor), and phones/cables have been usurped by distributed technologies such as satellite dishes and cell phones. 


\subsubsection{Potential for decentralised energy}

A thriving marketplace exists all over India that provides these alternatives to individual customers under a wide range of contractual arrangements such as leasing diesel gensets, outright purchase, and others. However, comprehensive data of a high quality about this marketplace is not available for India. Not only is basic data - e.g. sales of diesel generators - not readily available, there is not much data available about the usage of these alternatives (e.g. hours of use for a typical lead acid battery). Market research firms provide estimates - see for example 6WResearch (2016). To be sure, lack of data does not imply that these alternatives do not exist. In reality, the Indian end-user demand for electricity has always been met through a combination of centralised system, and decentralised alternatives in sharp contrast to the situation in the developed world (including China). The extent of the decentralised system is not comprehensively quantified although numerous case studies have been done that provide a useful qualitative picture.

From a cost-effectiveness perspective relative to the centralised system most of the alternatives listed above are massively more expensive than the centralised system. For example, running a diesel generator is twice as expensive as even the most expensive retail tariff for electricity from the centralised system. Similarly, kerosene lanterns are among the most expensive ways of providing lighting. However, given the unreliability and often availability of the centralised system, the user is - in fact - assessing the cost effectiveness of the alternatives relative to having to forego the service (e.g. lighting) in its entirety.

It is in this context that one has to examine the role of new technologies such as distributed solar, batteries, more efficient equipment (e.g. LEDs), and others and assess the factors that influence their adoption. In India, distributed solar PV systems are - fundamentally - not competing with electricity from the unreliable Indian centralised system but with the substantially expensive distributed alternatives (e.g. diesel generators, etc.) that have been historically used to supplement the centralised system. Initially, solar PV was significantly more expensive than these alternatives.

From a meeting of the reliability needs of a consumer - the comparison between the two sources of distributed generation (i.e. rooftop PV and diesel) is not straightforward for two reasons:

- solar PV is available only during day-time and if there is sufficient space available for its installation while diesel generators are available on demand and have a relatively small footprint;

- the upfront (or fixed) costs of the current alternatives (e.g. diesel generators or kerosene lanterns) are relatively low with high variable costs in sharp contrast to that of solar PV - as availability of cheap credit is limited for most consumers. 
Yet - the value proposition has started becoming so compelling that even the key manufacturers of diesel generators in India (e.g. Jakson, Sukam, Kirloskar, etc.) have added solar PV to their portfolios - whether independently or hybridised with diesel generators (Paul 2015). For example, Jakson Inc. - one of the main diesel generators in India - forecast in 2014 that within three years half of their sales would be from solar PV (Pearson 2014).

Not only is solar PV successfully competing against alternatives such as diesel generators, it has also now started competing against the retail tariffs faced by commercial and industrial (C\&I) customers in India for the electricity they purchase from the centralised system - see Prayas Energy Group (2017) and Bloomberg New Energy Finance, 2017. The high retail tariffs for C\&I customers in India is a consequence of the distinct policy environment which is discussed in more detail in the next section. For now, we simply note that these high retail tariffs are unlikely to decrease in the future - see Central Electricity Authority (2018) for trend in Average Revenue Recovered (i.e. average retail tariff) by discoms.

The Indian national and state policymakers have in recent years announced and initiated the implementation of several policies to support distributed solar PV. Forty GW out of a total of $100 \mathrm{GW}$ of solar PV that is set as the national target for 2022 is allocated to rooftop PV. However, discoms have started confronting the distinct possibility that the early adopters are likely to be their larger and wealthier consumers. These consumers provide the cross-subsidy that sustains the utility cash flow. If the utility sales to these large consumers falter, then there would be an immediate and significantly adverse impact on the utility financial situation. Consequently, utilities in many parts of India have started resisting the growth of rooftop PV that has led to rumours that the 40 GW policy target may end up being revised downward significantly. However, there is not much anyone can do when consumers install behind-the-meter rooftop PV systems that simply and passively offsets their consumption from the grid. From the discom's perspective, this appears similar to load that has vanished somewhat akin to but a potentially significantly larger impact than that of energy efficiency or demand response.

\subsubsection{The drivers of decentralised energy}

These circumstances - i.e. unreliability, increasing costs of the centralised system, and cost effectiveness of rooftop PV relative to retail tariff for a growing number of its customers - are unlikely to change in the future creating an attractive market for distributed solar PV without any policies and programs designed to promote it. In this section, we discuss in more detail why these circumstances are likely to persist in the future.

Historically, electricity has been one of a number of public goods for which the government was seen to be the sole provider. On paper - there are specific 
departments for each type of infrastructure - e.g. the state electricity distribution companies, municipal transport and housing authorities, centrally owned railways, etc. However, from the citizens' perspective, it was the state government that was supposed to provide them with electricity, just as it was meant to provide roads, healthcare, education, water, sanitation, public safety, etc. The electricity ratepayers of the government-owned utility also are the voters that state governments care about at election time. Issues like the cost of electricity to consumers not only come up in regulatory proceedings but also routinely show up in politics - see for example Dubash, Kale and Bharvirkar (2018).

Within India's federal division of power, state governments have the lion's share of authority in the electricity sector. After independence in 1947, the hundreds of small private utilities that generated and distributed electricity throughout the subcontinent were gradually subsumed into State Electricity Boards that were wholly owned by the respective state governments. In the first few decades post-Independence, the majority of the investment in the power sector was made by the state governments.

Over the last 15-20 years, these SEBs were unbundled into generation, transmission, and distribution companies. The national government has been attempting to introduce amendments to the 2003 Electricity Act with the goal of introducing full retail competition. However, there has been sustained resistance from the state governments to this step.

Significant investment from the central government and private sector has been made in the generation-side of the power sector, even today, state governments own most of the electricity distribution companies in India.

The world of the state government-owned distribution companies consists of trying to both expand massively its electricity distribution network (remember the 200-300 million customers with no access and the fact that India's population is still growing rapidly) and maintain the existing one, which has high wear-and-tear and as customers need increasing amounts of electricity to power air conditioners and other conveniences. All of this must take place in a context in which the retail tariff at which electricity can be sold to customers (also voters!) is fundamentally subject to political constraints and therefore remains low.

Given that India is still a poor country with many competing demands for limited government resources, it is difficult for state governments to come up with direct subsidies to keep the price of electricity low for its citizens, particularly the electorally significant agricultural users and low-income households. The alternative, which most state governments have chosen, is to achieve that outcome by charging richer and larger customers, who are typically commercial and industrial users, higher-than-cost tariffs while charging low income and agricultural customers tariffs that often approach zero. ${ }^{27}$ This cross-subsidy

${ }^{27}$ From a techno-economic perspective, the cost of providing service to large (e.g. C\&I and urban residential) customers is the least due to economies of scale and density 
system-in effect, based on the same principle as a progressive income tax policy_runs into obvious limitations. Beyond a certain point, richer and larger customers will either invest in their own electricity supply and/or leave the service territory completely. Either circumstance worsens the already difficult situation of the state-owned distribution utilities. Consequently, the distribution companies are constantly trying to strike a balance between their mandate to provide reliable power to all customers (also voters!) while keeping the costs at a level that are deemed politically acceptable.

From a broader perspective - i.e. how Indian citizens have received a wide range of services similar to electricity - the experience has been that the centralised system has consistently been unable to keep up with the demand. Consequently, Indian citizens have been forced to develop alternatives to the centralised systems in many aspects of their lives. Barring some solely centralised and publicly provided services (e.g. national security, roads, railways, etc.), decentralised and privately provided services supplement (even substitute) the centralised system in case of services such as education, transportation, electricity, water, healthcare, food, and others.

The service most analogous to electricity is water. And this example, too, is telling. Unlike in western countries, most Indian cities have not been able to supply their citizens with 24-7 water through a centralised pipeline system. Consequently, almost all households and businesses have water storage tanks. Some households have multiple. Many households have private 'bore wells' that run deep underground to access subterranean aquifers; others hire companies to deliver water in private tankers. Similarly, since the quality of the water is poor, households rely on a host of purification technologies installed and operated at the point of consumption.

As the costs of decentralised systems in the electricity domain continue to decrease - i.e. rooftop PV (analogous to bore wells in the water infrastructure above) and batteries (analogous to water storage tanks in the water infrastructure above) - it is quite possible that the electricity system would also evolve into a hybrid system similar to the water supply system. The problem is that the current water system (and the future potential electricity system) is not optimally designed, implemented, and operated in this hybrid form - but has simply evolved in a haphazard manner. A more thoughtful approach that actively incorporates both forms of centralised and decentralised systems in order to minimise the overall costs to society would be beneficial. For example, the distribution utilities may want to formally incorporate the decentralised systems (both spatially and temporally) while designing and operating their distribution grid infrastructure and making their wholesale level procurement decisions. Retail tariff designs could be considered that provide appropriate signals

and highest for the small (e.g. rural and agriculture) customers. Consequently, the cross-subsidy mechanism is, especially, unattractive for large customers. 
to consumers as they determine which decentralised systems to invest in. Currently - the distribution utilities have either ignored the existence of the ad hoc decentralised systems or resisted them outright.

Acknowledging that there are important variations across states in India, we can nevertheless make some general observations about the prevailing equilibrium: distribution companies are starved of capital to expand, an Indian population equivalent to that of the United States remains without electricity connections, and everyone else has a poor quality of service. However much the bureaucrats, engineers, and politicians who work in India's central and state governments might yearn to achieve their ultimate objectives of 24-7 power for all through the centralised system, they are constrained by political and economic conditions. Consequently, the status quo for the quality of the service provided by the centralised system is unlikely to change in the near term.

\subsubsection{Outcomes}

As discussed in the previous two sections, the existence of decentralised alternatives in India, albeit non-RE-based, long pre-dates the current interest in the United States and European Union for supporting decentralised RE-based alternatives. The circumstances that sustain the existence of these decentralised alternatives are unlikely to change substantively in the near term. And as the cost of RE-based decentralised technologies drops below that of existing decentralised technologies and the cost of electricity from the centralised grid, the uptake of RE is likely to continue. This uptake of decentralised RE is likely to take place independent of government policies and programs. For example, Prayas Energy Group (2017) has estimated that when the levelised cost of rooftop PV system reaches Rs. 5 per kWh in India - in nine major states in India, more than 50 per cent of the non-agricultural sales would find it cost effective to start switching to rooftop PV. In five of those nine states, the proportions is more than 70 per cent. As per BNEF (2017), all across India, prices for rooftop PV discovered through auctions have already sunk well below Rs. 4 per kWh with the minimum prices being observed as low as Rs. 2.38 per kWh.

Appropriately designed and implemented government policies and programs could expedite this uptake significantly. While poorly designed and implemented policies and programs may at best not influence the rate of uptake but at worst, is likely to slow it down. In this section, we discuss the implications of the existing policies/programs and suggest some approaches worth considering.

Most of the policy mechanisms currently being implemented or considered in India are adapted from those in the developed countries (e.g. the United States) where the value proposition for decentralised technologies is fundamentally different than that in India. To reiterate - decentralised technologies in India compete with an unreliable (sometimes non-existent) and an increasingly 
expensive centralised system. Unlike a typical customer in the developed world that expects the centralised system to be extremely reliable and affordable, the expectation of a typical Indian customer is to be able to pay for the level of reliability they seek and can afford. Indian policies can better take into account these two unique conditions in order to develop approaches that are better suited for the Indian context.

One possibility is a national-level program similar to the successful LEDdistribution program (http://www.ujala.gov.in) for solar PV panels, batteries, and inverters could be implemented that would streamline the availability of those products significantly while ensuring their quality at the lowest cost possible (through aggregation of demand and negotiating with manufacturers). Further, storage in the form of electricity (i.e. batteries and inverters) is not necessarily the only way to store useful energy. Thermal storage systems such as ice for space cooling and water heaters are a mature technology that could be deployed where appropriate. Other distributed systems such as geothermal heat-pumps can also be considered as the technology matures.

There would be no subsidies involved as the program is designed in the form of a loan that is recovered through an on-bill financing mechanism in partnership with the local utility. A wide range of sizes of technology (i.e. make full use of the modularity of the technology!) could be available to customers through this program for procurement either individually or in the form of cooperative arrangements. In conjunction with this technology dissemination program, retail tariffs could be re-designed to ensure that the costs/benefits are shared fairly between the utility and the customers. Both the approaches described here don't' rely on large financial commitments from the government and instead attempt to make full use of the existing demand for these technologies. For programs aimed at specific end-uses - e.g. agricultural pumps - the design must ensure that negative indirect impacts (e.g. water/land overuse) are minimised if not avoided through the use of a comprehensive portfolio of policies that go beyond the power sector (e.g. crop selection, water-use efficiency, etc.).

In India, the centralised power system will continue to provide a certain level of reliable electricity supply at prices established through a process that remains essentially political.

Outside of this bound, though, customers will continue to enhance their supply from the outside, where options have evolved from no electricity to lead-acid batteries and diesel generators, and now to solar PV and advanced batteries. In the absence of a more thoughtful approach to designing and operating the grid (e.g. retail tariff design) - the hybrid form of the power sector will evolve in a chaotic manner thereby imposing needless costs on the society. The goal of the policymakers - then - is to find ways to ensure their thinking about the future power sector is not largely restricted to the centralised system with decentralised systems a mere after-thought at best or outright nuisance at worst - but one of the important components of the power sector that can yield even lower costs for all. 


\subsubsection{References}

6WResearch. (2016), India diesel genset market (2018-2023), GWresearch, June 2017. Retrieved from http://www.6wresearch.com/market-reports/ india-diesel-genset-generator-market-2018-2023-forecast-by-kva-ratingverticals-commercial-and-industrial-regions-competitive-landscape.html

Bansal, S. (2016, March 26), On paper, electrified villages - in reality, darkness. The Hindu. Retrieved from http://www.thehindu.com/opinion/op-ed/ On-paper-electrified-villages- percentE2 percent80 percent94-in-realitydarkness/article14176223.ece

Bloomberg New Energy Finance. (2017), Accelerating India's clean energy transition: the future of rooftop $P V$ and other distributed energy markets in India. Retrieved September 16, 2018, from https://data.bloomberglp.com/bnef/ sites/14/2017/11/BNEF_Accelerating-Indias-Clean-Energy-Transition_ Nov-2017.pdf

Central Electricity Authority. (2018a), Executive summary on power sector. Retrieved September 16, 2018, from http://cea.nic.in/reports/monthly/ executivesummary/2018/exe_summary-07.pdf

Central Electricity Authority. (2018b), Growth of electricity sector in India from 1947-2017. Retrieved September 16, 2018, from www.cea.nic.in/ reports/others/planning/pdm/growth_2017.pdf

Deshmukh, R., Bharvirkar, R., Gambhir, A. \& Phadke, A. (2012), Changing sunshine: analyzing the dynamics of solar electricity policies in the global context. Renewable and Sustainable Energy Reviews, 16 (7).

Dubash, N., Kale, S. \& Bharvirkar, R. (2018), Mapping power: the political economy of electricity in India's states. Oxford: Oxford University Press.

Patel, D. (2016, September 14), All villages electrified, but darkness pervades. Indian Express. Retrieved from http://indianexpress.com/article/india/ india-news-india/electricity-in-india-villages-problems-still-no-lightpoverty-3030107/

Paul, C. (2015, January 7), Policy changes and private enterprise to boost greener India with cleaner fuel. Forbes India. Retrieved from http://www. forbesindia.com/printcontent/39311

Pearson, N. (2014, May 12), Jakson says solar to match diesel-generator sales by 2017. Bloomberg. Retrieved from https://www.bloomberg.com/news/ articles/2014-05-12/jakson-expects-solar-to-match-diesel-sales-by-2017

Prayas Energy Group. (2017), The price of plenty: insights from "surplus" power in Indian states. Retrieved September 16, 2018, from http://www. prayaspune.org/peg/publications/item/335-the-price-of-plenty-insightsfrom-surplus-power-in-indian-states.html

Sharma, A., Josey, A. \& Sreekumar, N. (2016), Lessons for rural electrification from a weaving village. India Together. Retrieved from http://indiatogether. org/lessons-for-rural-electrification-from-a-weaving-village-government 
Sengupta, D. (2016, July 26), Contrary to government's claims, small towns, rural areas still suffer from power outages. Energyworld. Retrieved from https://energy.economictimes.indiatimes.com/news/power/contraryto-governments-claims-small-towns-rural-areas-still-suffer-from-poweroutages $/ 53393538$ 